\title{
POTENCIAL PEDOCLIMÁTICO DO ESTADO DA PARAÍBA PARA A CULTURA DA MAMONA (RICINUS COMMUNIS L.)
}

\author{
Pedoclimatic Potential of the Paraiba State for Culture of the Castor Bean (Ricinus communis L.)
}

Paulo Roberto Megna Francisco ${ }^{1 *}$; Djail Santos²; Eduardo Rodrigues Viana de Lima ${ }^{3}$

${ }^{1}$ Pesquisador DCR CNPq/Fapesq; Universidade Federal da Paraíba; paulomegna@gmail.com

2 Prof. Titular; Departamento de Solos e Engenharia Rural; Universidade Federal da Paraíba; santosdj@cca.ufpb.br

${ }_{2}^{2}$ Prof. Adjunto; Departamento de Geociências; Universidade Federal da Paraíba; eduvianalima@gmail.com

Artigo enviado em 07/03/2017, aceito em 18/04/2017 e publicado em 07/07/2017.

Resumo - Este trabalho objetivou avaliar o potencial pedoclimático do Estado da Paraíba para a cultura da mamona. $\mathrm{Na}$ obtenção dos mapas de potencial pedoclimático, as informações do potencial dos solos, obtidas foram cruzadas com os da aptidão climática considerando três cenários pluviométricos: anos chuvosos, regulares e secos. O cruzamento das informações foi realizado por meio de técnicas de geoprocessamento utilizando o software SPRING e obtendo-se os mapas do potencial pedoclimático. O resultado das interpretações foi classificado em cinco classes de potencial pedoclimático: Muito Alto, Alto, Médio, Baixo e Muito Baixo. Os resultados encontrados possibilitam a definição dos ambientes de potencial efetivo para exploração agrícola com vistas à alocação racional dos fatores de produção e seu desempenho econômico, fornecendo elementos para a introdução de áreas não tradicionais; Deve ser levado em conta, que a precisão das informações apresentadas nas conclusões deste trabalho está diretamente relacionada ao nível imposto pela escala do levantamento de solo (1:200.000), base deste trabalho, e com isso há a possibilidade de cultivo da mamona em pequenas áreas que não puderam ser identificadas; São observadas diferenças significativas na extensão territorial das classes e subclasses de potencial pedoclimático do Estado da Paraíba, que apresenta variações de ordem pedológica e climática em seu território, influenciando no potencial pedoclimático para a cultura da mamona; O potencial pedoclimático Muito Alto não foi representado no mapeamento. As áreas de potencial pedoclimático Alto ocorrem principalmente na região do Litoral sul e pequenas áreas na região do Brejo. Os ambientes de potencial Médio ocorrem distribuídas nas regiões do Agreste, Brejo e Sertão. As áreas de potencial Baixo ocorrem no Curimataú e as áreas de potencial Muito Baixo ocorrem em quase todo Estado. A exigência hídrica e pedológica para a cultura da mamona restringe as áreas de plantio no Estado.

Palavras-Chave - Geotecnologias, planejamento de uso da terra, potencial pedológico, probabilidade, aptidão climática.

\begin{abstract}
This study aimed to evaluate the potential of the soil and climate of Paraiba State for of castor bean. In obtaining the pedoclimatic potential maps, the soil potential of information obtained were combined with the obtained climate suitability considering three rainfall scenarios: wet years, dry and regular. The crossing of the information was carried out through geoprocessing techniques using the SPRING software and obtaining maps of soil and climate potential. The result of the interpretations was classified into five pedoclimatic potential classes: Very High, High, Medium, Low and Very Low. The results obtained make it possible to define the effective potential environments for farm with a view to rational allocation of production factors and their economic performance by providing elements for the introduction of non-traditional areas; Should be taken into account that the accuracy of the information contained in the conclusions of this work is directly related to the level imposed by the scale of the soil survey (1: $200,000)$, the basis of this work, and thus there is a possibility of castor bean cultivation in small areas that could not be identified; significant differences are observed in the territorial extension of the classes and subclasses of potential soil and climate of the state of Paraiba, presenting variations of pedological and climatic order in their territory, influencing the potential soil and climate for the cultivation of castor bean; The potential pedoclimatic Very High was not represented in the mapping. Areas of high pedoclimatic potential occur mainly in the South Coast region and small areas in the Brejo region. The medium potential environments occur in the Agreste, Brejo and Sertão regions. Low Potential areas occur in the Curimataú and the Very Low potential areas occur in almost every State. The water and pedological demand for castor bean plantation restricts the planting areas in the state.
\end{abstract}

Keywords - Geotechnology, use planning of land, pedological potential, probability, climate aptitude. 


\section{INTRODUÇÃO}

A mamona (Ricinus communis L.) pertence à família Euphorbiaceae, que engloba um vasto número de espécies nativas da região tropical e possui origem discutida (BRITO NETO et al., 2008). Do fruto se extrai um óleo de excelentes propriedades e de grande uso como insumo industrial, sendo utilizada desde a antiguidade por suas propriedades medicinais (BARBOSA; NASCIMENTO, 2011). É classificada como uma planta xerófila, de clima tropical e subtropical, e seu cultivo têm sido intensificado até mesmo fora dos trópicos e subtrópicos (SOUZA et al., 2009). Bastante encontrada no semiárido nordestino, é uma euforbiácea resistente às estiagens e exigente em calor e luminosidade (SILVA, 1983).

Seu cultivo comercial ocorre, praticamente, em todos os estados da região Nordeste, que é responsável por $94 \%$ da área plantada com a cultura no país e por $87 \%$ da produção nacional de bagas (EMBRAPA, 2008). É uma importante alternativa de cultivo para a região do semiárido nordestino, por ser de fácil condução, boa resistência à seca, além de proporcionar ocupação e renda (EMBRAPA, 2008). A mamoneira é uma oleaginosa de relevante importância econômica, apresentando inúmeras aplicações na área industrial e com perspectivas de utilização como fonte de energia (SOUZA et al., 2009), sendo muito empregada na extração de óleo, para lubrificação de motores e na fabricação de tinta, verniz, plástico, saboaria, perfumaria, entre outros (AZEVEDO; LIMA, 2001).

Barbosa e Nascimento (2011), entendem que realizar o estudo sobre a produção da mamona no Estado paraibano, se torna importante, ao propor uma abordagem acerca do plantio da mamona, que poderá ocasionar um maior desenvolvimento regional e inclusão social, proporcionados pela geração de renda e emprego aos pequenos agricultores e seus familiares.

De acordo com Amorin Neto et al. (2001), a mamoneira, embora seja uma planta rústica, que se adapta com facilidade às diversas condições de ambiente, e que pode ser encontrada em todas as regiões brasileiras, só alcança produtividade e qualidade satisfatórias de seu produto comercial, quando cultivada em determinadas condições edafoclimáticas.

Entre as espécies cultivadas economicamente no Brasil, a mamoneira é uma das menos exigentes em termos de clima, solo e manejo cultural (AMORIM NETO et al., 2001). De acordo com EMBRAPA (2012), a mamona adapta-se bem à maioria dos solos, com exceção daqueles com problemas de drenagem e de textura muito argilosa ( $>60 \%$ de argila). Solos muito férteis favorecem o crescimento vegetativo excessivo, prolongando o período de maturidade e floração (SILVA et al., 2000). Os solos mais indicados para seu cultivo são os de textura franca e franco-argilosa, profundos, bem drenados, porosos, não compactados (HEMERLY, 1981), com fertilidade média, $\mathrm{pH}$ na faixa de 6,0 a 6,8 e sem problemas de salinidade e sodicidade (AZEVEDO et al., 1997).

A mamona é uma planta de clima tropical e por isso prefere locais de temperatura do ar variando entre 20 e $30^{\circ} \mathrm{C}$, precipitações pluviais mínimas de $500 \mathrm{~mm}$, elevada insolação, e baixa umidade relativa do ar, durante a maior parte do seu ciclo (BELTRÃO; SOUZA, 2003). De acordo com EMBRAPA (2012), a mamona é considerada uma espécie de dias longos e o seu desenvolvimento é beneficiado em fotoperíodos maiores que 12 horas. O ótimo ecológico da cultura da mamona apresenta temperatura de $23^{\circ} \mathrm{C}$, precipitações em torno de $1.000 \mathrm{~mm} . \mathrm{ano}^{-1}$, mas pode variar entre 500 a $1.600 \mathrm{~mm} \cdot \mathrm{ano}^{-1}$, bem distribuídos com rendimentos em torno de $1.500 \mathrm{~kg}^{-h^{-1}}$ (BELTRÃO; SILVA, 1999).

De acordo com Silva et al. (2013), a aptidão pedológica refere-se às potencialidades e limitações intrínsecas dos solos para a produção das culturas de forma sustentável, inter-relacionando parâmetros e atributos. Marques et al. (2010) afirmam que na avaliação do potencial de um determinado ambiente para produção de lavouras nas condições naturais (cultivo de sequeiro) basicamente são consideradas as exigências das culturas em relação ao solo (aptidão pedológica) e em relação ao clima (aptidão climática). A partir do cruzamento dessas avaliações, chega-se à aptidão pedoclimática. Esta última, de fato, é a que melhor representa o potencial efetivo do ambiente para a produção agrícola do ponto de vista social, econômico e ambiental.

O Estado da Paraíba, com área de $56.372 \mathrm{~km}^{2}$, apresenta variações significativas em relação a solo, geologia, clima, vegetação e recursos hídricos. De acordo com EMBRAPA (2013), esta variação ambiental produz espaços com diferentes potencialidades de exploração agrossilvopastoril e riscos de degradação ambiental. No entanto, o conhecimento destas variações é de fundamental importância quando se pretende implantar estratégias de desenvolvimento rural em bases sustentáveis.

Portanto, este trabalho objetiva associar e mapear as informações de ordem pedológica e climática, caracterizando e indicando o potencial pedoclimático do Estado da Paraíba para a cultura da mamona.

\section{MATERIAL E MÉTODOS}

A área de estudo compreende o Estado da Paraíba que apresenta uma área de $56.372 \mathrm{~km}^{2}$. Localiza-se entre os paralelos $6^{\circ} 02^{\prime} 12^{\prime \prime}$ e $8^{\circ} 19^{\prime} 18^{\prime \prime} \mathrm{S}$, e entre os meridianos de $34^{\circ} 45^{\prime} 54^{\prime \prime}$ e $38^{\circ} 45^{\prime} 45^{\prime \prime} \mathrm{W}$ (FRANCISCO, 2010). O clima caracteriza-se por temperaturas médias elevadas, variando entre 22 a $30^{\circ} \mathrm{C}$, amplitude térmica anual muito pequena, em função da baixa latitude e elevações 
$(<700 \mathrm{~m})$. A precipitação varia entre 400 a $800 \mathrm{~mm}$ anuais, nas regiões interiores semiáridas, e no Litoral, mais úmido, pode ultrapassar os 1.600mm (VAREJÃOSILVA et al., 1984).

O relevo apresenta-se de forma geral bastante diversificado, constituindo-se por formas de relevo diferentes trabalhadas por diferentes processos, atuando sob climas distintos e sobre rochas pouco ou muito diferenciadas. No tocante à geomorfologia, existem dois grupos formados pelos tipos climáticos mais significativos: úmido, subúmido e semiárido. O uso atual e a cobertura vegetal caracterizam-se por formações florestais definidas como caatinga arbustiva arbórea aberta, caatinga arbustiva arbórea fechada, caatinga arbórea fechada, tabuleiro costeiro, mangues, mataúmida, mata semidecidual, mata atlântica e restinga (PARAÍBA, 2006).

As classes predominantes de solos área de estudo (Figura 1) estão descritas no Zoneamento Agropecuário do Estado da Paraíba (PARAÍBA, 1978), e estas diferem pela diversidade geológica, pedológica e geomorfológica, atendendo também a uma diversidade de atributos do solo, relacionadas à morfologia, cor, textura, estrutura, declividade e pedregosidade e outras características como observou Francisco (2010).

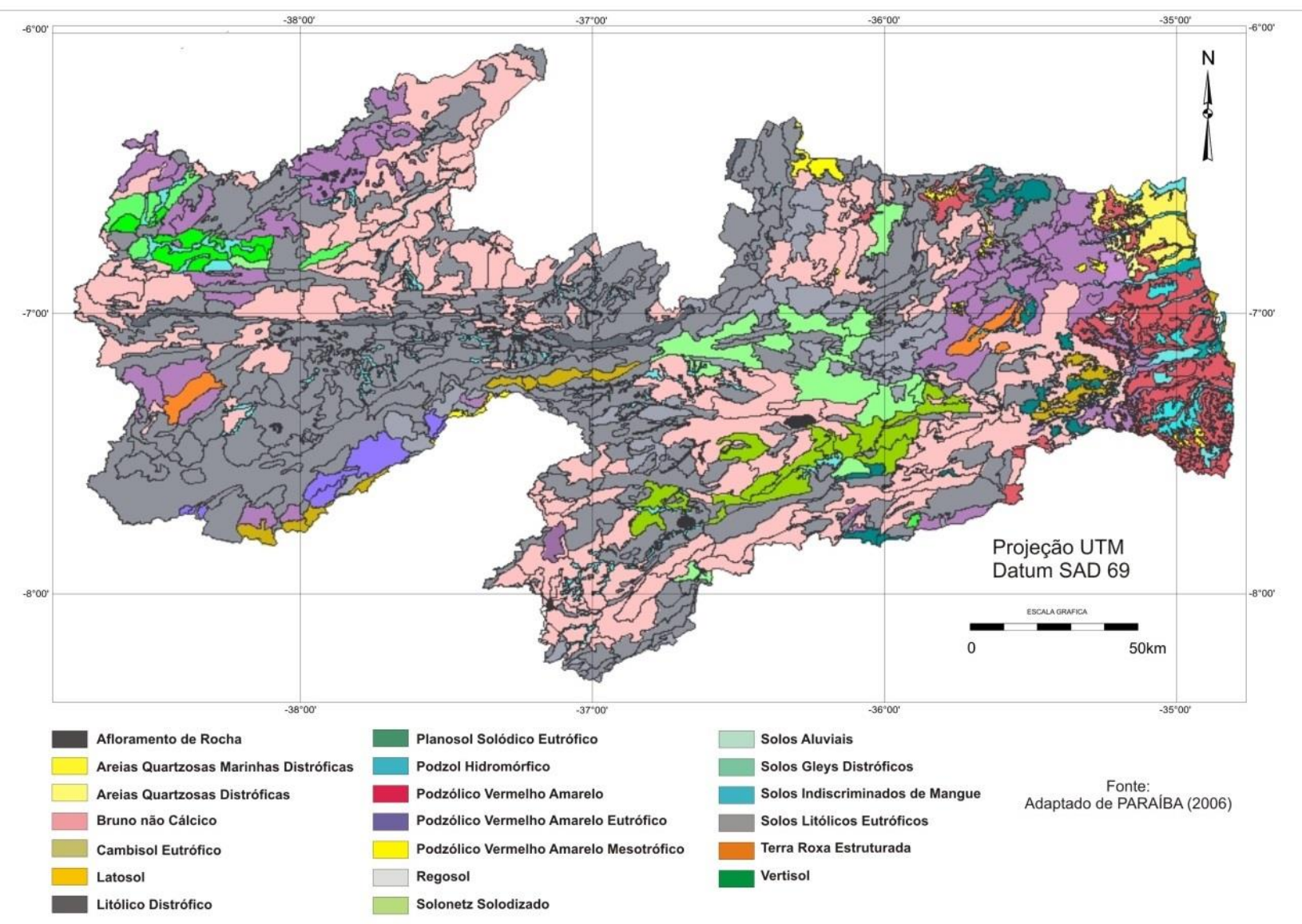

Figura 1. Solos do Estado da Paraíba. Fonte: Francisco et al. (2013).

Da interpretação dos dados pedológicos, as classes de capacidade de uso dos solos da Paraíba foram determinadas segundo os critérios originalmente propostos por Lepsch et al. (1996), adaptados na forma de chave interpretativa dos atributos da terra, que são descritas no Zoneamento Agropecuário do Estado da Paraíba (PARAÍBA, 1978). Por esta classificação as alternativas de uso estão limitadas pelo grau e pela natureza das restrições, impostos por um ou mais atributos da terra, levando em conta também a possibilidade de melhorias da terra, pela adoção de práticas conservacionistas, que compreendem além das práticas de controle da erosão, as complementares de melhoramento do solo.

Neste trabalho para elaboração do mapa do potencial pedológico foi utilizado como base cartográfica, os arquivos montados por Francisco et al. (2014), elaborados no software SPRING 5.2.2 na projeção UTM/SAD69, que contém o mapa digital de solos do Plano Estadual de Recursos Hídricos (PARAÍBA, 2006), atualizado em seus limites conforme IBGE (2009). 
Para representação do mapa de classe de capacidade de uso da terra, adotou-se a interpretação realizada no Zoneamento Agropecuário do Estado da Paraíba (PARAÍBA, 1978) atribuindo-se às classes de capacidade de uso as cores da legenda conforme Lepsch et al. (1996).

No estabelecimento do potencial pedológico aplicado no zoneamento da cultura da mamona (PARAÍBA, 1978), as terras foram classificadas de acordo com o grau de adaptabilidade ao desenvolvimento da cultura, para um nível de manejo B. Neste é admitido à aplicação mais ou menos intensiva de capital e um razoável nível de conhecimento técnico especializado, para a melhoria das condições dos solos e das culturas, que incluem tração motorizada e técnicas de correção e adubação recomendadas pela pesquisa agrícola.

$\mathrm{Na}$ interpretação para a cultura da mamona as terras foram agrupadas em Classes de Aptidão, subdivididas em Categorias, procurando-se representar conjuntamente as potencialidades das associações dos solos, componentes de cada uma das unidades de mapeamento (Tabela 1).

Tabela 1. Interpretação do potencial pedológico para a cultura da mamona

\begin{tabular}{|c|c|c|c|c|}
\hline Categoria & Aptidão & Potencialidades & $\begin{array}{c}\text { Classes de capacidade de } \\
\text { uso do Potencial de } \\
\text { Terras correspondente a } \\
\text { categoria }\end{array}$ & $\begin{array}{l}\text { Classes } \\
\text { utilizada }\end{array}$ \\
\hline 1 & Plena & $\begin{array}{l}\text { Áreas com classes e/ou associações de classes de } \\
\text { capacidade de uso, que são próprias para a cultura com } \\
\text { limitações ligeiras de utilização, impostas pelas } \\
\text { características dos solos, topografia e erosão }\end{array}$ & $A$ e B & Muito Alto \\
\hline $1 \mathrm{a}$ & Plena & $\begin{array}{l}\text { Áreas com associações de classes de capacidade de uso } \\
\text { com dominância de terras próprias para culturas, que } \\
\text { apresentam limitações ligeiras de utilização, impostas } \\
\text { pelas características dos solos, topografia e erosão }\end{array}$ & $\mathrm{C}$ e C1 & Alto \\
\hline 2 & Moderada & $\begin{array}{l}\text { Áreas com classes de capacidade de uso com limitações } \\
\text { moderadas para utilização com a cultura, devido as } \\
\text { características de fertilidade e/ou topografia }\end{array}$ & D1 & Média \\
\hline $2 \mathrm{a}$ & Moderada & $\begin{array}{l}\text { Áreas com associações de classes de capacidade de uso da } \\
\text { Categoria } 2 \text { agrupadas com terras próprias para pastagens }\end{array}$ & D1 & Média \\
\hline $2 \mathrm{~b}$ & Moderada & $\begin{array}{c}\text { Áreas com associações de classes de capacidade com } \\
\text { fortes limitações para a utilização com a cultura devido as } \\
\text { características de drenagem e associação de classes de } \\
\text { terras inaptas a cultura }\end{array}$ & D2 & Média \\
\hline $2 c$ & Moderada & $\begin{array}{c}\text { Áreas com classes de capacidade com limitações severas } \\
\text { para a utilização com a cultura devido as características de } \\
\text { drenagem imperfeita e associação de classes de terras } \\
\text { inaptas a cultura }\end{array}$ & $\mathrm{F}$ & Média \\
\hline 3 & Restrita & $\begin{array}{l}\text { Áreas com classes de capacidade de uso com limitações } \\
\text { fortes para utilização com a cultura, devido as } \\
\text { características de baixa fertilidade do solo e/ou drenagem } \\
\text { excessiva }\end{array}$ & D2 & Baixo \\
\hline I & Inapta & $\begin{array}{l}\text { Áreas impróprias para a exploração com a cultura, sendo } \\
\text { representada por classes de capacidade de uso ou } \\
\text { associações de classes cujas características dos solos e/ou } \\
\text { topografia apresentam restrições severas para utilização }\end{array}$ & Demais categorias & Muito Baixo \\
\hline
\end{tabular}

Nesta interpretação considerou-se apenas o potencial dos solos em sistema de manejo $B$, que se caracteriza por aplicação mais ou menos intensiva do capital e um razoável nível de conhecimentos técnicos especializados, para a melhoria das condições dos solos e das culturas, não se justificando nem um baixo, nem um muito alto nível de manejo, com resultados duvidosos principalmente do ponto de vista econômico. As práticas de manejo são levadas a efeito, na maioria dos casos, com auxílio de tração motorizada e utilizando-se de resultados de pesquisas agrícolas.
Para viabilizar a elaboração do mapa do potencial pedológico e também visando à padronização cartográfica os mapas foram categorizados de acordo com metodologia adaptada de EMBRAPA (2012) nas seguintes classes: Muito Alto - Categoria 1 (Aptidão Plena); Alto - Categoria 1a (Aptidão Plena); Média Categoria 2, 2a, 2b e 2c (Aptidão Moderada); Baixo Categoria 3 (Aptidão Restrita); Muito Baixo - Categoria I (Inapta).

Para a elaboração do potencial climático utilizaram-se os totais mensais de precipitações obtidos 
nos postos pluviométricos da Agência Executiva de Gestão das Águas do Estado da Paraíba (AESA-PB). A utilização dos dados foi procedida de uma análise no tocante à sua consistência, homogeneização e no preenchimento de falhas em cada série. Para cada localidade com série de observação igual ou superior a vinte anos, foi considerado para a utilização dos dados, independente do início.

$\mathrm{Na}$ elaboração deste trabalho foram estimadas as médias mensais de temperatura do ar naqueles locais onde apenas se dispunham de dados de chuva. $\mathrm{Na}$ metodologia adotada foram utilizados valores da temperatura média do ar dos últimos 30 anos estimados pelo software Estima_T (CAVALCANTI; SILVA, 1994; CAVALCANTI et al., 2006). Na elaboração do mapa de pluviosidade foi utilizada a metodologia proposta por EMBRAPA (2012) e adaptada para o Estado da Paraíba por Francisco et al. (2015).

A discriminação dos cenários pluviométricos, anos secos, regulares e chuvosos, seguiu a metodologia proposta por EMBRAPA (2002). Para cada posto pluviométrico, foi estabelecido o total de precipitação pluviométrica registrado nos três meses consecutivos mais chuvosos de cada ano hidrológico completo. Em seguida, a distribuição gama incompleta (ASSIS et al., 1996), seguindo a conceituação de Thom (1958), foi ajustada à série desses totais em cada posto, seguindo a metodologia indicada por Mielke (1976) e utilizada pela EMBRAPA (2012). A qualidade do ajustamento da curva teórica aos valores observados foi verificada pelo teste de Kolmogorov-Smirnov (MASSEY, 1980) ao nível de significância de 95\%. Esses mesmos critérios foram aplicados em todas as séries pluviométricas. Como a curva de distribuição da chuva acumulada nos três meses consecutivos mais chuvosos é específica para cada posto, os valores correspondentes às probabilidades de 25, 50 e 75\% também são específicos de cada posto (VAREJÃO-SILVA, 2001).

Os conjuntos dos anos secos, regulares e chuvosos de cada posto foram utilizados para obter as correspondentes médias mensais dos totais pluviométricos, necessárias para caracterizar os respectivos cenários. Os critérios para discriminar os anos hidrológicos de cada posto pluviométrico foram enquadrados em uma das categorias indicadas (VAREJÃO-SILVA, 2001):

a) Anos secos - aqueles em que o total de precipitação, acumulado nos três meses consecutivos mais chuvosos, for igual ou menor que o valor correspondente à probabilidade de $25 \%$;

b) Anos chuvosos - aqueles cujo total de precipitação, acumulado nos três meses consecutivos mais chuvosos, é superior ao valor correspondente à probabilidade de $75 \%$;

c) Anos regulares - todos aqueles anos não classificados nas duas categorias anteriores.

No cálculo do índice de umidade foi utilizada a equação do balanço hídrico climatológico segundo Thornthwaite e Mather (1955), onde o Índice de umidade (Iu) de acordo com a expressão:

$$
\boldsymbol{I} \boldsymbol{u}=\boldsymbol{I h}-\boldsymbol{I a}(1)
$$

Em que: o índice hídrico (Ih) e índice de aridez (Ia) são calculados respectivamente por:

$$
\begin{aligned}
& \boldsymbol{I h}=100\left(\frac{\text { Exc }}{\text { ETP }}\right) \\
& \boldsymbol{I} \boldsymbol{a}=100\left(\frac{\text { Def }}{\boldsymbol{E T P}}\right)
\end{aligned}
$$

Em que: excedente hídrico (Exc), evapotranspiração (ETP) e deficiência hídrica (Def).

Para avaliação de aptidão climática da cultura da mamona foram utilizados os critérios conforme a metodologia adaptada de EMBRAPA (2012), onde o índice efetivo de umidade (Iu) foi utilizado como parâmetro (Tabela 2).

Tabela 2. Critérios utilizados na avaliação de aptidão climática da cultura da mamona

\begin{tabular}{ccc}
\hline Legenda & Aptidão Climática & Índice de umidade (Iu) \\
\hline C3 & Moderada por excesso hídrico & Iu $\geq 20$ \\
C2 & Plena com período chuvoso prolongado & $-10<\mathrm{Iu} \leq 20$ \\
C1 & Plena & $-20<\mathrm{Iu} \leq-10$ \\
C4 & Moderada por deficiência hídrica & $-40<\mathrm{Iu} \leq-20$ \\
C5 & Inapta por deficiência hídrica acentuada & $\mathrm{Iu} \leq-40$ \\
\hline
\end{tabular}

Fonte: Adaptado de EMBRAPA (2012).

Na metodologia de trabalho, após a obtenção dos mapas do potencial pedológico e dos mapas da aptidão climática, nos cenários pluviométricos com anos chuvosos, regulares e secos, foram cruzados através da Linguagem Espacial Geográfica Algébrica (LEGAL), utilizando o software SPRING, e obtiveram-se os mapas do potencial pedoclimático do Estado da Paraíba para a cultura em estudo. As classes prováveis obtidas foram 5 classes e 25 subclasses do potencial pedoclimático (Tabela 3). 
Tabela 3. Classes e subclasses de potencial pedoclimático

\begin{tabular}{cccccc}
\hline & \multicolumn{5}{c}{ Aptidão climática (C) } \\
\cline { 2 - 6 } $\begin{array}{c}\text { Potencial } \\
\text { pedológic } \\
\text { o (S) }\end{array}$ & $\begin{array}{c}\text { C1 - } \\
\text { Plen } \\
\mathbf{a}\end{array}$ & $\begin{array}{c}\text { Plen } \\
\text { a } \\
\text { (PCP } \\
\text { ) }\end{array}$ & $\begin{array}{c}\text { C3 - } \\
\text { Moderad } \\
\text { a (EH) }\end{array}$ & $\begin{array}{c}\text { C4 - } \\
\text { Moderad } \\
\text { a (DH) }\end{array}$ & $\begin{array}{c}\text { C5 - } \\
\text { Inapt } \\
\mathbf{a}\end{array}$ \\
\hline $\begin{array}{c}\text { S1- } \\
\text { Muito } \\
\text { Alto }\end{array}$ & MA1 & MA2 & M3 & M4 & MB5 \\
S2 - Alto & A3 & A4 & M5 & M6 & MB6 \\
$\begin{array}{c}\text { S3 - } \\
\text { Médio }\end{array}$ & M1 & M2 & M7 & M8 & MB7 \\
S4 - Baixo & B1 & B2 & B3 & B4 & MB8 \\
S5 - Muito & MB1 & MB2 & MB3 & MB4 & MB9 \\
Baixo & Maixo
\end{tabular}

$\mathrm{PCP}=$ Período chuvoso prolongado; $\mathrm{EH}=$ Excesso hídrico;

$\mathrm{DH}=$ Deficiência hídrica; MA=Muito Alta; $\mathrm{A}=\mathrm{Alta} ; \mathrm{M}=$ Médio;

$\mathrm{B}=$ Baixo; $\mathrm{MB}=$ Muito Baixo

Fonte: Adaptado de EMBRAPA (2012).

Conforme a metodologia da EMBRAPA (2012), o potencial pedoclimático é restringido pela limitação de solo e/ou de clima que ocorrer com maior intensidade no ambiente. Por exemplo, ambiente com potencial pedológico Alto e com aptidão climática Inapta, terá seu potencial pedoclimático limitado pelo clima. Da mesma forma, as áreas com clima favorável ao cultivo, mas com potencial pedológico restritivo, terão o potencial pedoclimático limitado por atributos de solo.

\section{RESULTADOS E DISCUSSÃO}

Pelos resultados obtidos, observa-se no mapa de Potencial pedológico para a cultura da mamona, que não se identificou-se terras com Potencial Muito Alto (Figura 2).

De acordo com o mapa de Potencial pedológico para a cultura da mamona, identificou-se $2.805,45 \mathrm{~km}^{2}$ de terras com Potencial Alto, representando 4,98\% (Tabela 4) da área total do Estado distribuídas no Litoral e Agreste ao sul do Estado divisa com Pernambuco, na área norte do Curimataú próximo à divisa com o Rio Grande do Norte, e no Alto Sertão e na região oeste do Sertão na divisa com o Ceará.

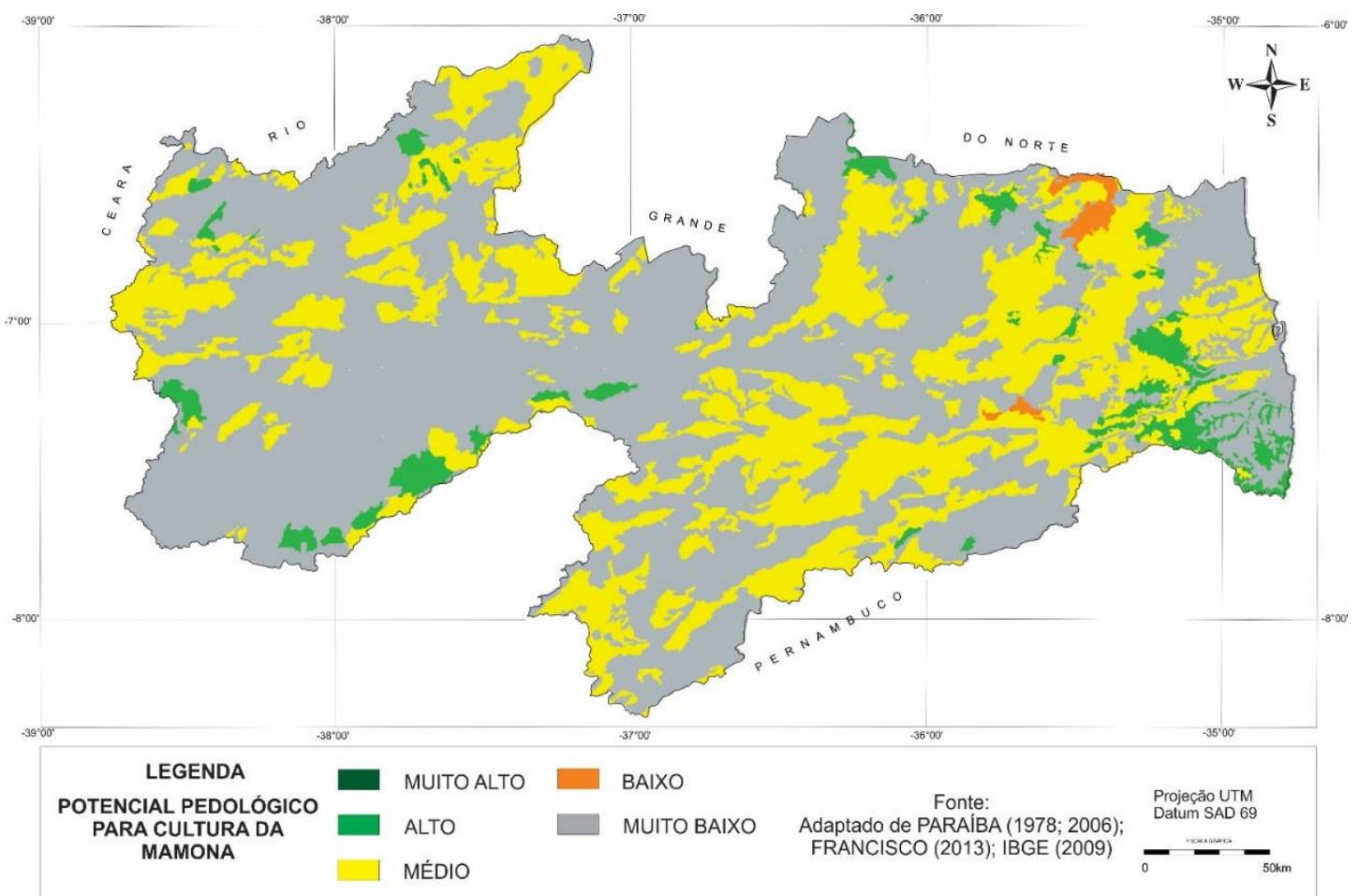

Figura 2. Potencial pedológico das terras do Estado da Paraíba para a cultura da mamona.

Observa-se neste trabalho que as áreas com Potencial Médio perfazem um total de 19.675,69 km², representando $34,9 \%$ da área total e estão distribuídas por todo o Estado. As áreas com Potencial Baixo, observada por este trabalho, perfazem um total de
$328,09 \mathrm{~km}^{2}$, representando $0,58 \%$ da área total do Estado, localizadas na região do Agreste ao Norte. As áreas com Potencial Muito Baixo perfazem um total de $33.562,77 \mathrm{~km}^{2}$ de terras, correspondendo a 59,54\% da área total distribuídas por todo o Estado. 
Tabela 4. Distribuição das classes do potencial pedológico da cultura da mamona

\begin{tabular}{|c|c|c|c|c|c|c|c|c|c|c|c|}
\hline \multicolumn{12}{|c|}{ Classes do Potencial Pedológico } \\
\hline \multicolumn{2}{|c|}{ Muito Alto } & \multicolumn{2}{|c|}{ Alto } & \multicolumn{2}{|c|}{ Médio } & \multicolumn{2}{|c|}{ Baixo } & \multicolumn{2}{|c|}{ Muito Baixo } & \multicolumn{2}{|c|}{ Total } \\
\hline $\mathrm{km}^{2}$ & $\%$ & $\mathrm{~km}^{2}$ & $\%$ & $\mathrm{~km}^{2}$ & $\%$ & $\mathrm{~km}^{2}$ & $\%$ & $\mathrm{~km}^{2}$ & $\%$ & $\mathrm{~km}^{2}$ & $\%$ \\
\hline 0,00 & 0,00 & $2.805,45$ & 4,98 & $19.675,69$ & 34,90 & 328,09 & 0,58 & $33.562,77$ & 59,54 & $56.372,00$ & 100,00 \\
\hline
\end{tabular}

No mapa de aptidão climática da mamona no cenário regular, com 50\% de probabilidade (Figura 3), observa-se o predomínio da classe de aptidão Inapta por deficiência hídrica acentuada (C5), em 51,79\% da área, representando 29.192,17 $\mathrm{km}^{2}$ (Tabela 5), abrangendo parte da região do Agreste, Cariri e Curimataú, e parte do Sertão.

Para a classe de aptidão Moderada por deficiência hídrica (C4), observa-se que ocorre em 38,31\%, ocupando 21.594,78 km² da área do Estado. Estas áreas ocorrem na região do Sertão do Estado e em parte do Agreste e Brejo.

No mapa de aptidão climática para a cultura da mamona, observa-se que este não apresentou área mapeada para a aptidão climática Moderada por excesso hídrico (C3). Para a classe de aptidão climática Plena com período chuvoso prolongado (C2), observa-se uma área de $3.734,04 \mathrm{~km}^{2}$ representando $6,62 \%$ da área total, que ocorre em toda a faixa Litorânea de altitudes baixas, e em parte da região do Brejo, no município de Areia, e contemplando o munícipio de Campina Grande, região do Agreste entre as altitudes de 500 a $600 \mathrm{~m}$. A classe de aptidão Plena (C1), com 1.851,01 km² representando $3,28 \%$ da área total, ocorre nas regiões do Agreste e Brejo, circundando os municípios de Campina Grande e Areia, e ocorrendo numa faixa estreita próxima ao Litoral e entre as classes C2 e C4.

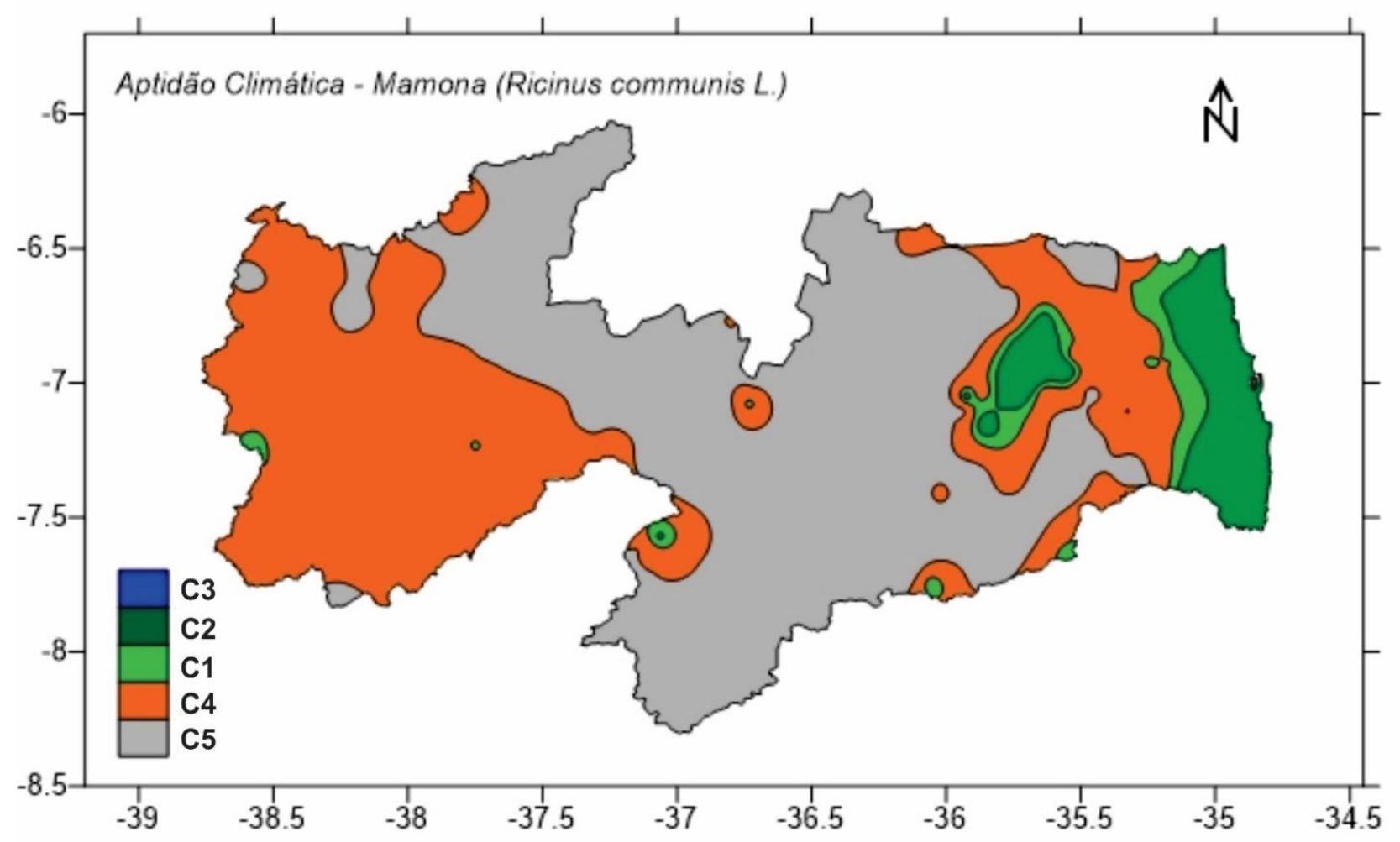

Figura 3. Aptidão climática para cultura da mamona.

Tabela 5. Classes de aptidão climática para cultura da mamona

\begin{tabular}{cccc}
\hline \multirow{2}{*}{ Legenda } & Aptidão climática & \multicolumn{2}{c}{ Cenário pluviométrico regular } \\
\cline { 3 - 4 } & Plena & $\mathbf{k m}^{\mathbf{2}}$ & $\mathbf{\%}$ \\
\hline C1 & $1.851,01$ & 3,28 \\
C2 & $3.734,04$ & 6,62 \\
C3 & Plena com período chuvoso prolongado & 0,00 & 0,00 \\
C4 & Moderada por excesso hídrico & $21.594,78$ & 38,31 \\
C5 & Moderada por deficiência hídrica & $29.192,17$ & 51,79 \\
\hline
\end{tabular}


No mapa de potencial pedoclimático da cultura da mamona (Figura 4), observa-se que o potencial Muito Alto não está representado no mapeamento. As áreas de potencial pedoclimático Alto abrangem $775,34 \mathrm{~km}^{2}$, representando $1,37 \%$ da área total (Tabela 6), com ocorrência das subclasses A3 e A4, predominando a subclasse A4. Estas classes ocorrem principalmente na região do Litoral sul e pequenas áreas na região do Brejo, notadamente em ambientes que apresentam solos de potencial pedológico Alto, e aptidão climática plena com período chuvoso prolongado. EMBRAPA (2013), encontrou resultados similares a este trabalho, em áreas relativamente pequenas e em manchas dispersas.

Os ambientes de potencial Médio abrangem $9.545,31 \mathrm{~km}^{2}$, representando $16,93 \%$ da área total, com ocorrência das subclasses M1, M2, M6 e M8, com predomínio da subclasse M8. Estas classes ocorrem distribuídas nas regiões do Agreste, Brejo e Sertão. Notadamente nestes ambientes por apresentarem solos de potencial pedológico Médio, e aptidão climática Plena e Moderada por deficiência. Francisco et al. (2013), observaram que as áreas de Aptidão Moderada perfizeram um total de $19.419,37 \mathrm{~km}^{2}$, representando $34,57 \%$ da área total. As áreas Inaptas perfizeram um total de $33.481,90 \mathrm{~km}^{2}$, correspondendo a $59,62 \%$ da área total.

As áreas de potencial Baixo contemplam os ambientes com fortes limitações de solo e/ou de clima, abrangem 148,90 $\mathrm{km}^{2}$, representando $0,26 \%$ da área total, com ocorrência somente da subclasse B4. As áreas de potencial Muito Baixo contemplam os ambientes com fortes limitações de solo e/ou de clima, abrangem $45.902,45 \mathrm{~km}^{2}$, representando $81,43 \%$ da área total, com ocorrência das subclasses MB1, MB2, MB4, MB6, MB7, MB8 e MB9, predominando a subclasse MB9. Estas classes ocorrem em quase todo Estado por apresentarem aptidão climática Inapta.

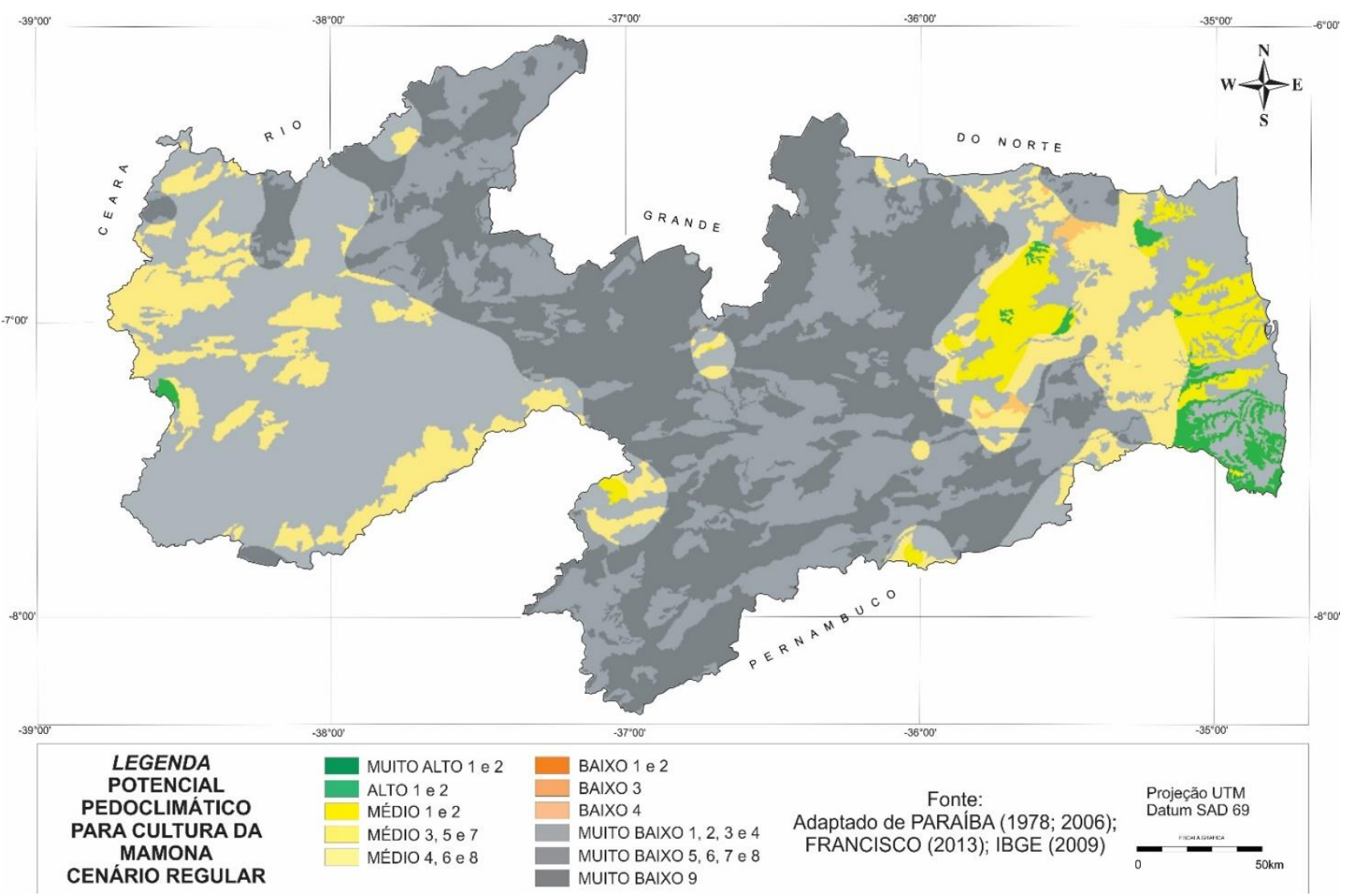

Figura 4. Potencial pedoclimático para cultura da mamona.

Francisco et al. (2013), observaram que as maiores limitações ocorridas são devidas aos solos predominantes: Luvissolo Hipocrômico Órtico, Planossolo Nátrico, Neossolo Litólico Eutrófico e Afloramentos de Rochas, que resumem limitações muito fortes, principalmente devidas à escassez de água nestas regiões, além da pequena profundidade dos solos, presença de pedregosidade e rochosidade, características estas que tornam difícil qualquer possibilidade de utilização agrícola ou pecuária nestas condições. Resultados similares foram encontrados neste trabalho.

Barros et al. (2015), elaborando o potencial pedoclimático do Estado de Alagoas, observaram resultados similares aos encontrados neste trabalho, 
relatando que esses ambientes com potencial Baixo e Muito Baixo, têm predomínio de solos rasos e pouco profundos, além de outros com caráter sódico/solódico e/ou sálico/salino; e ainda solos associados ao relevo movimentado e ao clima semiárido acentuado do Sertão.

Tabela 6. Classes de aptidão pedoclimática para cultura da mamona

\begin{tabular}{|c|c|c|c|}
\hline Classe & Subclasse & Cenário Regular & $\%$ Total \\
\hline \multirow{2}{*}{ Muito Alta } & MA1 & - & \\
\hline & MA2 & - & 0,00 \\
\hline \multirow{2}{*}{ Alta } & A3 & 271,74 & \\
\hline & A4 & 503,61 & 1,37 \\
\hline \multirow{8}{*}{ Média } & M1 & 819,23 & \\
\hline & M2 & $1.309,81$ & \\
\hline & M3 & - & \\
\hline & M4 & - & \\
\hline & M5 & - & \\
\hline & M6 & $1.584,50$ & \\
\hline & M7 & - & \\
\hline & M8 & $5.831,77$ & 16,93 \\
\hline \multirow{4}{*}{ Baixa } & B1 & - & \\
\hline & B2 & - & \\
\hline & B3 & - & \\
\hline & B4 & 148,90 & 0,26 \\
\hline \multirow{9}{*}{ Muito Baixa } & MB1 & 759,36 & \\
\hline & MB2 & $1.917,81$ & \\
\hline & MB3 & - & \\
\hline & MB4 & $14.015,55$ & \\
\hline & MB5 & - & \\
\hline & MB6 & 444,74 & \\
\hline & MB7 & $11.706,04$ & \\
\hline & MB8 & 178,38 & \\
\hline & MB9 & $16.880,59$ & 81,44 \\
\hline Total & & $56.372,00$ & 100,00 \\
\hline
\end{tabular}

Devido ao maior número de anos de dados pluviométricos, em relação ao trabalho elaborado por PARAIBA (1978) na aptidão pedoclimática, e ás pesquisas elaboradas por diversos autores, como exemplo a EMBRAPA (2013), em relação às necessidades hídricas da cultura da mamona, este trabalho demonstra diferenças geoespacializadas e em totais de áreas mapeadas, isso também devido à metodologia no uso dos limites das classes.

\section{CONCLUSÕES}

Os resultados encontrados possibilitam a definição dos ambientes de potencial efetivo para exploração agrícola, com vistas à alocação racional dos fatores de produção e seu desempenho econômico, fornecendo elementos para a introdução de áreas não tradicionais.

Deve ser levado em conta que a precisão das informações apresentadas nas conclusões deste trabalho, está diretamente relacionada ao nível imposto pela escala do levantamento de solo (1:200.000), base deste trabalho, e com isso há a possibilidade de cultivo da mamona em pequenas áreas que não puderam ser identificadas.

São observadas diferenças significativas na extensão territorial das classes e subclasses de potencial pedoclimático do Estado da Paraíba, que apresenta variações de ordem pedológica e climática em seu território, influenciando no potencial pedoclimático para a cultura da mamona.

O potencial pedoclimático Muito Alto não foi representado no mapeamento. As áreas de potencial pedoclimático Alto ocorrem principalmente na região do Litoral sul e pequenas áreas na região do Brejo. Os ambientes de potencial Médio ocorrem distribuídas nas regiões do Agreste, Brejo e Sertão. As áreas de potencial Baixo ocorrem no Curimataú e as áreas de potencial Muito Baixo ocorrem em quase todo Estado.

A exigência hídrica e pedológica para a cultura da mamona restringe as áreas de plantio no Estado.

\section{AGRADECIMENTOS}

Ao $\mathrm{CNPq} /$ Fapesq pela concessão de bolsa de pesquisa ao primeiro autor.

\section{REFERÊNCIAS}

AMORIM NETO, M. da S.; ARAÚJO, A. E. de; BELTRÃO, N. E. de M. Zoneamento agroecológico e época de semeadura para a mamoneira na Região Nordeste do Brasil. Revista Brasileira de Agrometeorologia, v.9, n.3, p.551-556, 2001.

ASSIS, F. N.; ARRUDA, H. V. de; PEREIRA, A. R. Aplicações de estatística à climatologia: teoria e prática. Pelotas: UFPel, 1996. 161p.

AZEVEDO, D. M. P. de; LIMA, E. F.; BATISTA, F. A. S. Recomendações técnicas para o cultivo da mamoneira (Ricinus communis L.) no Brasil. Circular técnica, 25. Campina Grande: EMBRAPA-CNPA, 1997. 52p.

AZEVEDO, D. M. P. de; LIMA, E. F. O agronegócio da mamona no Brasil. Brasília: Embrapa Informação Tecnológica, cap.3, 63-76. 2001.

AZEVEDO, D. M. P. de; LIMA, E. F. Zoneamento agroecológico e época de semeadura para a mamoneira na Região Nordeste do Brasil. Revista Brasileira de Agrometeorologia, v.9, p.551-556, 2001.

BARBOSA, J. S.; NASCIMENTO, A. J. S. O cultivo de mamona na Paraíba, como alternativa de plantio ao 
agricultor familiar. Revista Brasileira de Informações Cientificas, v.3, n.2, p.67-73, 2011.

BARROS, A. H. C.; OLIVEIRA NETO, M. B. de; MARQUES, F. A.; SILVA, A. B. DA; AMARAL, A. J. do; ARAÚJO FILHO, J. C. de. Potencial pedoclimático do Estado de Alagoas para a cultura da mamona. In: CONGRESSO BRASILEIRO DE CIÊNCIA DO SOLO, 35, Natal, 2015. Anais...Natal, 2015.

BELTRÃO, N. E. M.; SILVA, L. C. Os múltiplos usos do óleo da mamona (Ricinus communis L.) e a sua importância do seu cultivo no brasil. Fibras e Óleos, v.31, 1999.

BELTRÃO, N. E. M.; SOUZA J. G. Estresse hídrico (deficiência e excesso) e seus efeitos no crescimento inicial da mamoneira, cultivar BRS 188 Paraguaçu. Revista de Oleaginosas e Fibrosas, v.7, p.735-741, 2003.

BRITO NETO, J. F. de; SOUZA, K.S. de; GUEDES FILHO, D. H.; LACERDA, J. S. de; COSTA, D. S.; SANTOS, D.P. dos; SENA, G. S. A. de. Avaliação dos componentes de produção da mamoneira em função de doses de calcário e fósforo. In: REUNIÃO BRASILEIRA DE MANEJO DE SOLO E ÁGUA, 2008. Rio de Janeiro. Anais... Rio de Janeiro, 2008.

CAVALCANTI, E. P.; SILVA, E. D. V. Estimativa da temperatura do ar em função das coordenadas locais. In: CONGRESSO BRASILEIRO DE METEOROLOGIA, 8, 1994. Belo Horizonte, Anais...Belo Horizonte: SBMET, 1994, v.1, p.154-157.

CAVALCANTI, E. P.; SILVA, V. de P. R.; SOUSA, F. de A. S. Programa computacional para a estimativa da temperatura do ar para a região Nordeste do Brasil. Revista Brasileira de Engenharia Agricola e Ambiental, v.10, n.1, p.140-147, 2006.

EMBRAPA. CNPA. Cultivo da Mamona - Sistemas de Produção. Embrapa Algodão. 2008. Disponível em: http://www.cnpa.embrapa.br/produtos/mamona/. Acesso em: 19/06/2012.

EMBRAPA. Zoneamento Agroecológico do Estado de Alagoas - ZAAL. ViZon. Embrapa Solos, UEP Recife, 2013. CDROM.

FRANCISCO, P. R. M. Classificação e mapeamento das terras para mecanização do Estado da Paraíba utilizando sistemas de informações geográficas. 122f. Dissertação (Manejo de Solo e Água). Centro de Ciências Agrárias. Universidade Federal da Paraíba. Areia, 2010.

FRANCISCO, P. R. M.; CHAVES, I. de B.; LIMA, E. R. V. de. Classificação de terras para mecanização agrícola e sua aplicação para o Estado da Paraíba. Revista Educação Agrícola Superior, v.28, n.1, p.30-35, 2013.

FRANCISCO, P. R. M.; CHAVES, I. de B.; LIMA, E. R. V. de; SANTOS, D. Tecnologia da geoinformação aplicada no mapeamento das terras à mecanização agrícola. Revista Educação Agrícola Superior, v.29, n.1, p. 4551, 2014.

HEMERLY, F. X. Mamona: comportamento e tendências no Brasil. EMBRAPA-DTC. Documentos, 2. Brasília: EMBRAPA-DID, 1981. 69p.

IBGE. Instituto Brasileiro de Geografia e Estatística. 2009. Disponível em http://www.ibge.gov.br. Acesso em: 12 de março de 2011.

LEPSCH, I. F.; BELLINAZZI JR., R.; BERTOLINI, D.; ESPÍNDOLA, C. R. Manual para levantamento utilitário do meio físico e classificação de terras no sistema de capacidade de uso. 4 a Aprox. SBCS, Campinas-SP, 1996, 175p.

MARQUES, F. A.; ARAÚJO FILHO, J. C. de; BARROS, A. H. C.; LOPES, E. H. B.; BARBOSA, G. M. N. Aptidão pedoclimática das culturas dos feijões caupi e comum Para o estado de Alagoas. In: CONGRESSO BRASILEIRO DE CIÊNCIA DO SOLO, 33, Uberlândia, 2010. Anais...Uberlândia: RBCS, 2010. p.1-4.

MASSEY JR, F. J. The Kolmogorov-Smirnov test of goodness of fit. Journal of American Statistical Association, v.46, p.68-78, 1980.

MIELKE, P. W. Simple iterative procedures for twoparameter gamma distribution maximum likeliwood estimates. Journal of App. Meteorology, v.15, n.12, p.181183. 1976.

PARAÍBA. Governo do Estado. Secretaria de Agricultura e Abastecimento - CEPA-PB. Zoneamento Agropecuário do Estado da Paraíba. Relatório ZAP-B-D2146/1. UFPB-Eletro Consult Ltda., 1978. 448p.

PARAÍBA. Secretaria de Estado da Ciência e Tecnologia e do Meio Ambiente. Agência Executiva de Gestão de Águas do Estado da Paraíba, AESA. PERHPB: Plano Estadual de Recursos Hidricos: Resumo Executivo \&o Atlas. Brasília, DF, 2006. 112p.

SILVA, A. B. da; AMARAL, A. J. do; SANTOS, J. C. P. dos; GOMES, E. C.; MARQUES, F. A.; OLIVEIRA NETO, M. B. de. Potencial pedológico do Estado de Alagoas para o cultivo de cana-de-açúcar em manejo com alta tecnologia. In: CONGRESSO BRASILEIRO DE CIÊNCIA DO SOLO, 34, Florianópolis. Anais...Florianópolis, 2013. 
SILVA, A. DA. Mamona: potencialidades agroindustriais do Nordeste brasileiro. Recife: SUDENE-ADR, 1983. 154p.

SILVA, L. C.; NETO, M. S. A.; BELTRÃO, N. E. M. Recomendações técnicas para o cultivo e época de plantio de mamona cultivar BRS 149 nordestina na região de Irecê-BA. Comunicado Técnico, 112. Campina Grande: EmbrapaCNPA, 2000. 4p.

SOUZA, K. S. de; OLIVEIRA, F. A. de; GUEDES FILHO, D. H.; BRITO NETO, J. F. de. Avaliação dos componentes de produção da mamoneira em função de doses de calcário e fósforo. Revista Caatinga, v.22, p.116122, 2009.
THOM, H. C. S. A note on the gama distribution. Monthly Weather Review, v. 86, p. 117-122. 1958.

THORNTHWAITE, C. W.; MATHER, J. R. The water balance. Publications in Climatology. New Jersey: Drexel Institute of Technology, 104p. 1955.

VAREJÃO-SILVA, M. A. Meteorologia e climatologia. Brasília, DF: INMET, 515p. 2001.

VAREJÃO-SILVA, M. A.; BRAGA, C. C.; AGUIAR M. J. N.; NIETZCHE, M. H.; SILVA, B. B. Atlas Climatológico do Estado da Paraíba. UFPB, Campina Grande, 1984. 